
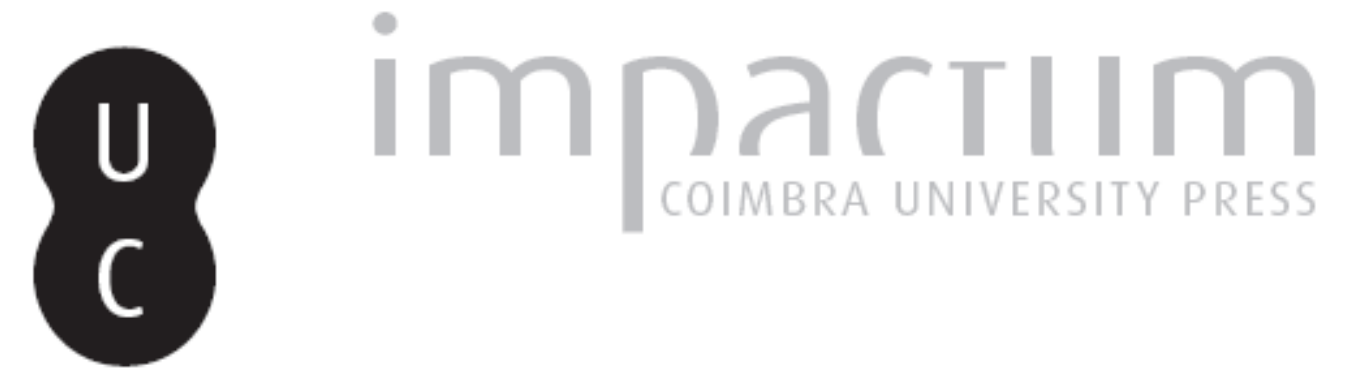
Estar-aí: a conquista poética de um espaço: uma exposição de Claudia Renault no
Colégio das Artes
Autor(es):
Hörster, Maria António
Publicado por: Faculdade de Letras da Universidade de Coimbra
URL
persistente:
URI:http://hdl.handle.net/10316.2/32359
DOI:
DOI:http://dx.doi.org/10.14195/0870-4112_10_15
Accessed : $\quad$ 26-Apr-2023 15:24:03

A navegação consulta e descarregamento dos títulos inseridos nas Bibliotecas Digitais UC Digitalis, UC Pombalina e UC Impactum, pressupõem a aceitação plena e sem reservas dos Termos e Condições de Uso destas Bibliotecas Digitais, disponíveis em https://digitalis.uc.pt/pt-pt/termos.

Conforme exposto nos referidos Termos e Condições de Uso, o descarregamento de títulos de acesso restrito requer uma licença válida de autorização devendo o utilizador aceder ao(s) documento(s) a partir de um endereço de IP da instituição detentora da supramencionada licença.

Ao utilizador é apenas permitido o descarregamento para uso pessoal, pelo que o emprego do(s) título(s) descarregado(s) para outro fim, designadamente comercial, carece de autorização do respetivo autor ou editor da obra.

Na medida em que todas as obras da UC Digitalis se encontram protegidas pelo Código do Direito de Autor e Direitos Conexos e demais legislação aplicável, toda a cópia, parcial ou total, deste documento, nos casos em que é legalmente admitida, deverá conter ou fazer-se acompanhar por este aviso. 

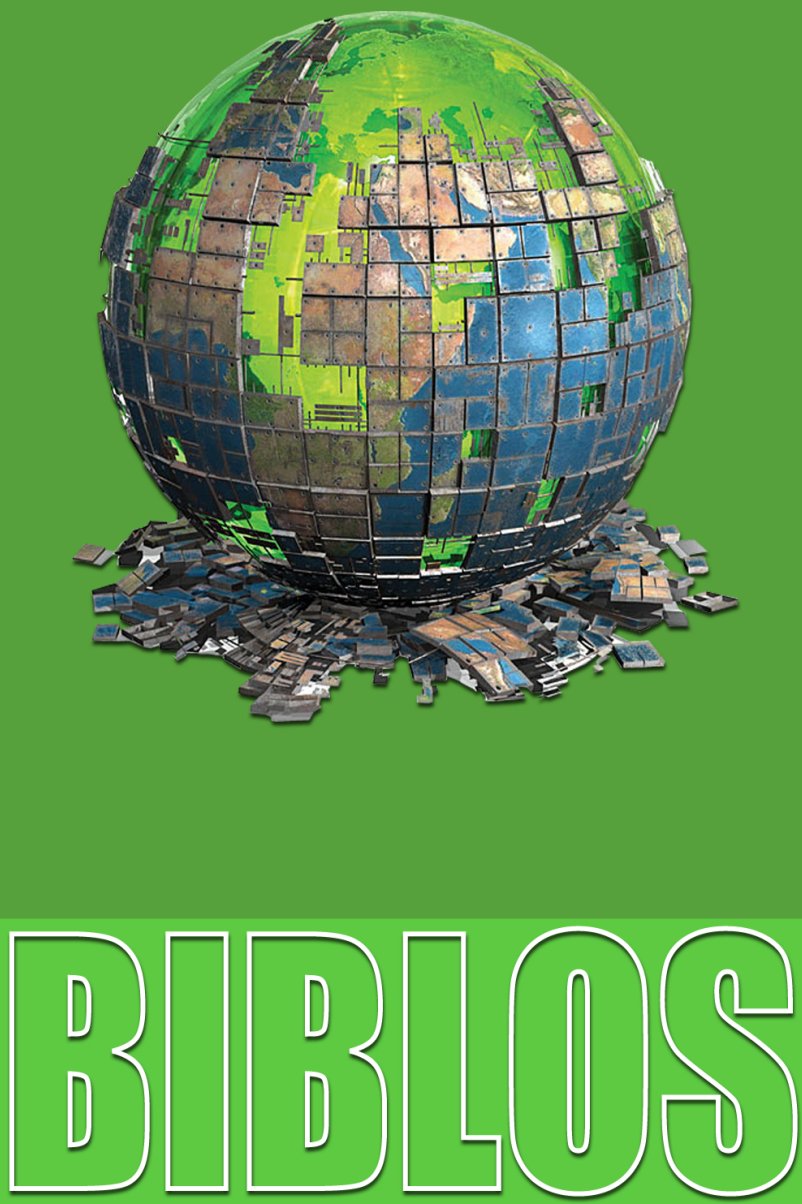

$\frac{\text { REVISTA DA FACULDADE DE LETRAS }}{\text { UNIVERSIDADE DE COIMBRA }}$ 
Biblos, n. s. X (2012) ...-...

Maria António Hörster

Faculdade de Letras da Universidade de Coimbra

\section{ESTAR-AÍ: A CONQUISTA POÉTICA DE UM ESPAÇO \\ UMA EXPOSIÇÃO DE CLAUDIA RENAULT NO COLÉGIO DAS ARTES}

Claudia Renault é uma artista plástica com nome firmado em Belo Horizonte, capital do Estado de Minas Gerais, cidade onde nasceu e reside. Tendo iniciado a sua carreira artística na sua cidade natal, começou por dedicar-se à xilogravura, partindo em seguida para a criação de objetos e instalações. Tem apresentado os seus trabalhos em múltiplas exposições, individuais e coletivas, dentro e fora do Brasil. Dentre estas, destacam-se algumas coletivas, como a mostra "Leiria, Belo Horizonte - um Encontro de Culturas", realizada na galeria 57, em Leiria, em 2000, ou as que decorreram na Galeria Marília Razuk, São Paulo - SP, em 2003, e no IDB Cultural Center, em Washington, EUA, em 2006. Claudia Renault encontra-se representada em importantes acervos como: Coleção Gilberto Chateaubriand - Rio de Janeiro R.J.; Museu de Arte da Pampulha, Belo Horizonte MG; Instituto Cultural Itaú, São Paulo SP, entre outros.

Ligada à carreira docente no domínio da Escola Guignard-UEMG, da Universidade do Estado de Minas Gerais, coordenou e foi chefe do Departamento de Artes Plásticas. Desde 2010 encontra-se a frequentar um Curso de Doutoramento em Arte Contemporânea, que abriu na Universidade de Coimbra, nesse ano.

Ora é justamente desta experiência que partiu o impulso para a sua mais recente exposição. $\mathrm{O}$ móbil exterior e imediato para apresentação dos seus últimos trabalhos foi uma exposição coletiva, acompanhada da apresentação global dos projetos de todos os participantes no Curso de Doutoramento, iniciativa com que a sua direção quis simbolicamente encerrar a parte curricular deste programa de estudos. Esta mostra coletiva abriu em 26 de outubro e decorreu nas instalações do imponente Colégio das Artes, o espaço que acolhe o curso. Paralelamente a essa 
mostra, e integrada no programa geral de abertura à comunidade, foi simultaneamente inaugurada uma exposição individual da artista brasileira, que se articula estreitamente com o seu projeto de doutoramento, submetido ao tema "Habitar como Poética". Os trabalhos que agora apresenta estendem-se por sucessivas salas do primeiro e segundo andar do edifício. E já aqui podemos falar numa poética do habitar. Efetivamente, com a anuência da direção do curso, Claudia Renault foi-se gradualmente familiarizando com e apropriando-se de espaços sem vida, fora de uso, degradados, des-habitados, do velho edifício, aos quais transmitiu, com as suas intervenções, uma dimensão estética nova.

Mas aquilo que o espetador agora pôde apreciar num recanto do claustro do Colégio e em cinco das suas salas, ligadas por uma escada interior, nasceu de um processo longo e silencioso de indagação e conquista de um lugar. Tem origem numa auscultação muda, regular, persistente, de uma cidade alheia, desconhecida - neste caso, Coimbra - em que o estranho e o familiar se conjugam. No percurso de sua casa para a universidade, palmilhado em silêncio dia após dia, Claudia Renault foi procurando pistas de existências, auscultando os sinais da existência de outros, recolhendo e juntando peças de um puzzle, em que nos reconhecemos como se nos víssemos ao espelho: os OUTROS e NÓS, os OUTROS e EU, os OUTROS como EU. E, neste processo de reconhecimento, com sobressalto mas também com alegria, descobrem-se os pequenos nadas do nosso quotidiano, as marcas da nossa leve e efémera passagem sobre a Terra.

Na sala que primeiro se oferece ao visitante cumprem-se, aparentemente, com maior "docilidade", as regras de uma exposição canónica: o material recolhido encontra-se montado sobre placas de vidro, material que a artista tem explorado em trabalhos seus anteriores (vd., por ex., Claudia Renault Belo Horizonte, Editora C/Arte, 2009), e aparentemente encontra-se organizado de acordo com critérios tradicionais, de forma, cor, tamanho, textura. É a vida orgânica que aqui encontramos, folhas secas de árvores e fragmentos de madeiras de todos os tipos, cortiça, sementes, mas também restos de canalizações, fragmentos de azulejos, detritos de materiais de construção, fundos de garrafas de vidro e latas amolgadas pela passagem de veículos, e muitas, inúmeras, pedras. Mas também as marcas arqueológicas de existências humanas, numa paleta que percorre idades, desejos, atividades, preocupações: restos de 
bengalas, de lentes de óculos, cartas de jogar, senhas de autocarros, papéis anotados com uma caligrafia certinha e minúscula, uma moldura vazia, evocando a memória de afetos que possa ter representado, na ilusória esperança de vir a ser re-habitada. Uma luva de borracha de algum operário, de um cinzento de morte, impõe-se-nos de repente, e está ali pelo gesto humano no tempo, simultaneamente investido e despojado de sentido. Mais escondida e discreta, e mais amorável, a caixinha de madeira que, de fato, transportou uma goiabada de São Lourenço, numa viagem de Minas Gerais a Coimbra. Claudia Renault mostra assim estar atenta às "coisas", no sentido que lhes dava Heidegger e que foi central na escrita de um poeta como Rainer Maria Rilke, pondo em evidência o seu ser "não-nada", na expressão do filósofo alemão.

Todo este material se encontra quase inocentemente alinhado em carreirinhas horizontais, como se de um catálogo se tratasse. E já aqui se instala o paradoxo e se reconhece o impulso artístico de todos os tempos: a tentativa de instaurar a ordem no caos. Mas o paradoxo abre caminho por outras vias ainda, como sejam o contraste entre a transparência das placas de vidro e a obscuridade do real, tentativamente reconstituído e decifrado pela acumulação dos múltiplos fragmentos que para ele apontam. Com esta valorização estética do fragmento, a artista inscreve-se numa linha já traçada pelos românticos alemães e explorada na modernidade.

Mas do plano humano, individual ou coletivo, que se dá à descoberta na sala principal da exposição, passa-se a outros espaços, num dos quais o espetador é convidado a confrontar-se com a pegada que deixa sobre a Terra. Claudia Renault aproveitou um compartimento interior, sem janela e sem luz natural, para montar uma instalação em que o chão se encontra pejado de pequenas garrafas de plástico, daquelas de que todos os dias nos servimos e deitamos fora, e cujas paredes são animadas por sacos de plástico, também eles brancos e transparentes, que, impulsionados por um foco de ar em movimento, nos acenam fantasmagoricamente, lembrando-nos não só os nossos atentados contra a mãe-natureza, mas sinalizando-nos igualmente a nossa efemeridade.

Num outro compartimento, encontra-se uma instalação de sinal radicalmente diferente: através de uma nesga de janela, somos convidados a ver, em filme, um pedaço de céu intensamente azul e luminoso, rasgado pelo movimento rápido de andorinhões, que a algazarra estrídula e vital das aves potencia. 
Assenta igualmente no paradoxo a montagem que ocupa um outro cubículo do Colégio. O centro é habitado pelo tronco ressequido de uma piteira, que, na sua verticalidade, nos força a dirigir o olhar para o alto: no teto, em plano superior, uma imagem luminosa de verdes e de frescura, que ora se acende em clarões ora se apaga, desmentindo a secura da coluna que a sustenta.

$\mathrm{E}$, também no primeiro andar, um último espaço, aparentemente o mais desarrumado, e também o mais agressivo, invadido por materiais resgatados do lixo, presenças fantasmáticas de objetos outrora úteis e familiares, como uma cadeira de escritório ou cadeirinhas de criança, velhas, agora desconchavadas e sem préstimo, memórias de anónimas existências humanas, na sua passagem pelo tempo. Ocorrem-nos os belíssimos versos de Camilo Pessanha: "Tantos naufrágios, perdições, destroços!/ - Ó fúlgida visão, linda mentira!// Róseas unhinhas que a maré partira... / Dentinhos que o vaivém desengastara.../ Conchas, pedrinhas, pedacinhos de ossos."

Mas não falámos ainda dos espaços de transição. Por um lado, o recanto do claustro, em que se encontra montada a escultura de estreia da artista: paletes de madeira empilhadas jogam em contraponto de linhas, de texturas e de valores, com um monte de estilhaços de vidro dispersos sobre a relva. Por outro lado, ainda, a escada, que regista, em mais de mil fotografias, uma atividade inversa. Se as outras salas testemunhavam o ato de recolha, estas fotografias dão conta de um outro movimento, o da dispersão. Mais recentemente, Claudia Renault tem feito arte de rua, discreta, mas insistente, colando, prendendo, juntando pequenos e menos pequenos objetos com que se defronta em espaços públicos, e fazendo assim realçar cada um deles pela inesperada junção ou estimulando com isso a criação de inesperadas e potenciais significações. Daí resultam novos objetos estéticos, humildes, efémeros, surpreendentes.

Jogando igualmente com a palavra poética, Claudia Renault inscreveu no topo das escadas um fragmento da escritora portuguesa Maria Gabriela Llansol, que funciona, por um lado, como mise en abyme dos trabalhos expostos, mas também, por outro, como registo de cariz autobiográfico e auto-avaliação do que tem sido a sua aventura coimbrã:

“__ Este é um abrigo na orla do bosque.

Metade árvore,

Metade construção de ramos mortos.

Como cada um chegou com a sua árvore (...)" 